Naunyn-Schmiedeberg's Arch. Pharmacol. 301, 129-134 (1977)

\title{
Effects of Guanidine on Synaptic Transmission in the Spinal Cord of the Frog*
}

P. GRAFE and U. SONNHOF, with technical assistance of A. KÜHNER

I. Physiologisches Institut, Universität Heideiberg, Im Neuenheimer Feld 326, D-6900 Heidelberg, Federal Republic of Germany

Summary. The effects of guanidine on motoneurons of the isolated frog spinal cord were studied by adding the drug to the solution bathing the cord during intracellular recording. Guanidine $\left(5 \cdot 10^{-4} \mathrm{M}\right)$ did not alter the membrane potential of motoneurons.

The main effect was a marked increase of the amplitudes and frequencies of small spontaneously occurring inhibitory postsynaptic potentials. The hyperpolarizing component of postsynaptic potentials evoked by stimulation of dorsal roots was also enhanced by guanidine. Higher concentrations of guanidine (5 $\cdot 10^{-3} \mathrm{M}$ ) resulted in a very large and irreversible increase of the small spontaneously occurring inhibitory potentials, which now appeared in a regular, rhythmic pattern.

The effects of guanidine could easily be blocked by increasing the magnesium ions $(15 \mathrm{mM})$ in the bath solution.

These results indicate that guanidine facilitates the release of an inhibitory transmitter in afferent terminals of the frog spinal cord either by a direct action on these terminals or indirectly by an action on nerve endings impinging on inhibitory interneurons.

Key words: Guanidine - Transmitter - Spinal Cord - Amyotrophic lateral sclerosis.

\section{INTRODUCTION}

As early as 1876 the effects of guanidine on the motor system of frogs were described by Gergens and Baumann to consist of 2 phenomena: the induction of

Send offprint requests to $\mathrm{P}$. Grafe and $\mathrm{U}$. Sonnhof at the above address

* This work was supported by the Deutsche Forschungsgemeinschaft fibrillary twitches of muscles combined with tonic extensor spasms of the extremities. They concluded that guanidine had 2 sites of action: one the neuromuscular junction and another the spinal cord. The action of guanidine on neuromuscular transmission was investigated in detail (Otsuka and Endo, 1960; Kamenskaya et al., 1975a, b; Teräväinen and Larsen, 1975) and has led to the clinical use of this drug in the treatment of botulism (Scaer et al., 1969; Ricker and Döll, 1970), and of the myasthenic syndrome (Lambert and Elmquist, 1971; Oh and Kim, 1973).

Only very little, however, is known about the effects of guanidine within the spinal cord (Koizumi, 1955). Based upon empirical data guanidine was proposed for the treatment of patients suffering from amyotrophic lateral sclerosis (Norris et al., 1974); its effectiveness was, however, not confirmed by Wiederholt (1975). Therefore, it seemed necessary to obtain more experimental results on the action of guanidine on synaptic transmission in spinal cord. For this purpose we used the isolated spinal cord of the frog. This preparation offers many advantages for pharmacological investigations (Sonnhof et al., 1975). In the present paper we report on the effects of guanidine on the membrane potential and on postsynaptic potentials of motoneurons.

\section{METHODS}

Experiments were performed on the frog, Rana esculenta, using a method described by Sonnhof et al. (1975). After decapitation a ventral laminectomy was performed in cooled Ringer solution. The spinal cord, including dorsal and ventrai roots of the lumbar segments, was removed and placed in a recording chamber consisting of a perspex block with a small groove (volume $1.5 \mathrm{ml}$ ), which was continuously superfused with Ringer solution by means of a roller pump ( $2 \mathrm{ml} / \mathrm{min}$ ). The Ringer solution contained (in $\mathrm{mM}$ ): $\mathrm{NaCl}$ 108.0, $\mathrm{KCl} 3.65, \mathrm{NaHCO}_{3} 12.0, \mathrm{CaCl}_{2} 1.5$ and additionally Dextrose $2 \mathrm{~g} / \mathrm{l}$. The temperature of the perfusion fluid was adjusted to $22^{\circ} \mathrm{C}$ by a Peltier element. Ventral and dorsal roots of the lumbar segments of one side were placed on silver wire electrodes for stimulation and 
covered with a mixture of paraffin and vaseline. Ringer solutions containing guanidine (guanidinium chloride, Merck) and high magnesium concentrations were stored in vessels which could be connected to the chamber during intracellular recording from motoneurons. All solutions were gassed with a mixture of $\mathrm{O}_{2}$ and $\mathrm{CO}_{2}$ and were $\mathrm{pH}$-stabilized at 7.4 with Tris-(hydroxymethyl)-methyl-2aminoethane-sulfonic acid. For insertion of microelectrodes the spinal meninges between ventral and dorsal roots were carefully removed. Recording electrodes (tip diameter below $1 \mu \mathrm{m}$ ) were filled with potassium acetate (3M). Stable intracellular records from motoneurons could frequently be achieved for several hours. The membrane potential was monitored continuously by a compensation writer and quick signals were displayed on oscilloscopes and recorded as photographs.

\section{RESULTS}

Successful intracellular records were obtained in 46 lumbar motoneurons of 17 isolated frog spinal cord preparations. Concentrations of guanidine in the bath solution from $10^{-4}$ to $5 \cdot 10^{-3} \mathrm{M}$ were used and the duration of exposure varied between 3 and $15 \mathrm{~min}$. A detailed investigation was performed with a concentration of $5 \cdot 10^{-4} \mathrm{M}$, because the effects of guanidine in this concentration were reversible. High concentrations $\left(5 \cdot 10^{-3}\right)$, however, caused irreversible changes of synaptic activity.

\section{Effects of Guanidine in Low Concentration $\left(5 \cdot 10^{-4} \mathrm{M}\right)$}

The main effect of guanidine was a marked increase in the amplitude and the frequency of the small, spontaneously occurring postsynaptic potentials. In Figure 1 a typical example for this action of guanidine is presented. In Figure 1A the resting membrane potential and the postsynaptic potentials (PSP) evoked by dorsal root (DR) stimulation (DR-PSP) of a motoneuron were recorded with a compensation writer. In addition, as shown in Figure $1 \mathrm{~B}$ the resting membrane potential is demonstrated with high speed and amplification from an oscilloscope. As can be seen in Figure $1 \mathrm{~B}_{1}$ also under normal conditions the membrane potential showed small irregular appearing oscillations. These small postsynaptic potentials of frog motoneurons were first described by Katz and Miledi (1963) and were called "spontaneous miniature potentials". Some minutes after the application of guanidine into the bath solution $\left(5 \cdot 10^{-4} \mathrm{M} / 7 \mathrm{~min}\right)$ these potentials strongly increased in amplitude and frequency (Fig. $1 \mathrm{~B}_{3}$ ). The membrane potential, however, was not changed. The effect of guanidine was reversible. About 20 min after the end of application all intracellular measurable signals reached their control values.
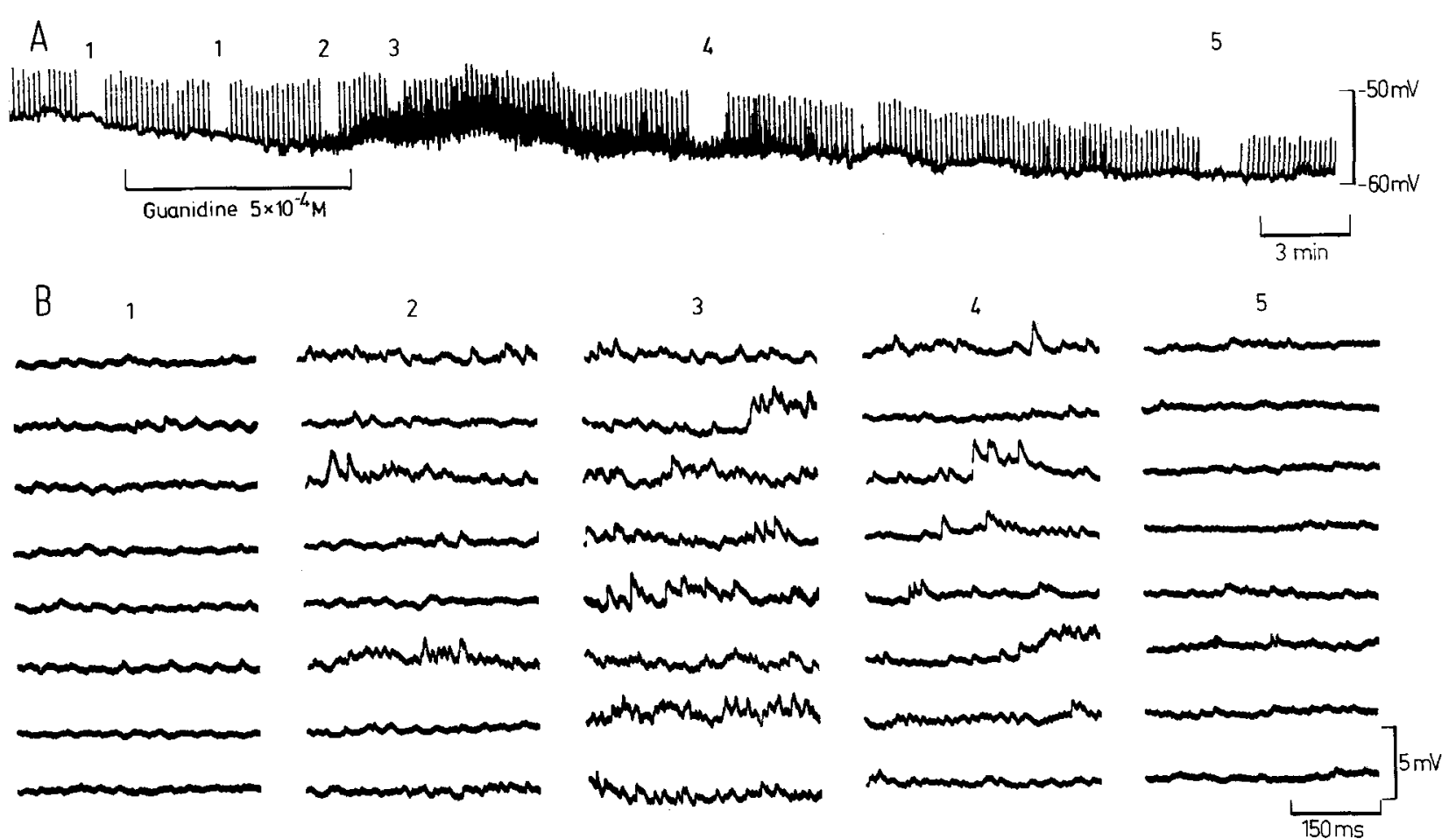

Fig. $1 \mathrm{~A}$ and B. Effect of guanidine in low concentration $\left(5 \cdot 10^{-4} \mathrm{M}\right.$ ). (A) Intracellular recording from a motoneuron. Postsynaptic potentials were induced by stimulation of a dorsal root (DR-PSP). Guanidine $\left(5 \cdot 10^{-4} \mathrm{M}\right.$ ) was present in the bath solution for 7 min (indicated by the horizontal bar below the record, transport time in the tube system was $2 \mathrm{~min}$ ). At the times indicated by the Figures $1-5$, stimulation of the dorsal root was stopped. (B) Tracings recorded at higher sweep speed and corresponding to the times indicated by the Figures $1-5$ in $A$. Continuous registration from top to bottom. Note, at this high amplification the small spontaneous postsynaptic potentials, which were markedly increased in amplitude and frequency by guanidine 
Fig. $2 \mathrm{~A}$ and $\mathrm{B}$

Changes of postsynaptic potentials (DR-PSP) during intracellular current injection. In A postsynaptic potentials induced by dorsal root stimulation (DRPSP) and the membrane potential were recorded with the compensation writer during intracellular current injections. In B corresponding DR-PSPs are photographed from the oscilloscope. Only depolarizing PSPs are recorded without current injection $(0 \mathrm{nA})$ in frog motoneurons. When the membrane potential, however, was decreased by intracellular current injections ( $6 \mathrm{nA} \mathrm{dep}$.) it was possible to differentiate between depolarizing and hyperpolarizing components of the evoked PSPs
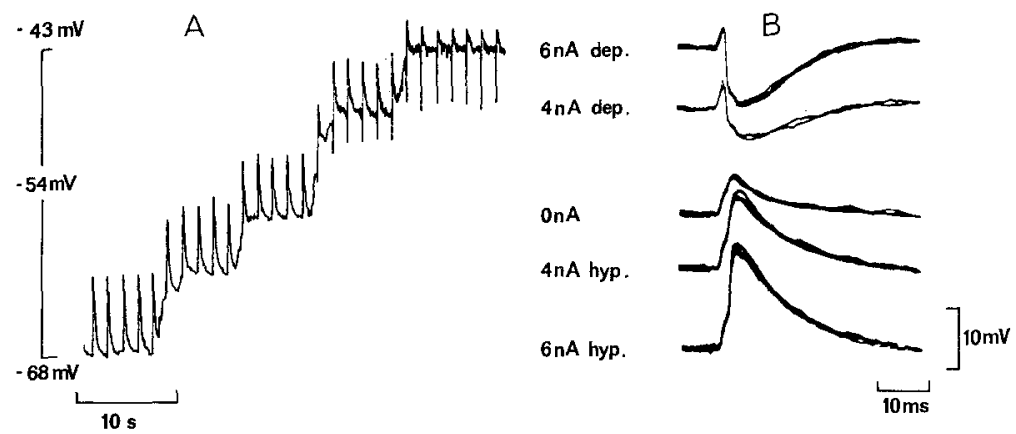

Fig. $3 \mathrm{~A}-\mathrm{D}$

Effect of guanidine in low concentration $\left(5 \cdot 10^{-4} \mathrm{M}\right)$ during intracellular current injection. The membrane potential of this motoneuron was depolarized by intracellular current injection $(5 \mathrm{nA})$ of sufficient strength for the appearance of hyperpolarizing inhibitory components of the DR-PSP (see Figs. 2B, 3C). (A and B) Same registration as in Figure 1. In part $B_{t}$ small spontaneous depolarizing EPSPs and hyperpolarizing IPSPs are visible. Note, that only the spontaneous IPSPs are increased by guanidine $\left(B_{2}\right)$. $(C)$ Before each period $1-3$ one stimulus induced postsynaptic potential (DR-PSP) was photographed from the oscilloscope. $\mathrm{C}, a$ represents the DR-EPSP and $\mathrm{C}, b, c$ mark the two parts of the DRIPSPs. (D) The DR-PSP before (upper trace) and during (lower trace) the action of guanidine are photographically superimposed. Note the increase in amplitude and the shortening of the latency of the first part $(b)$ of the DR-IPSP
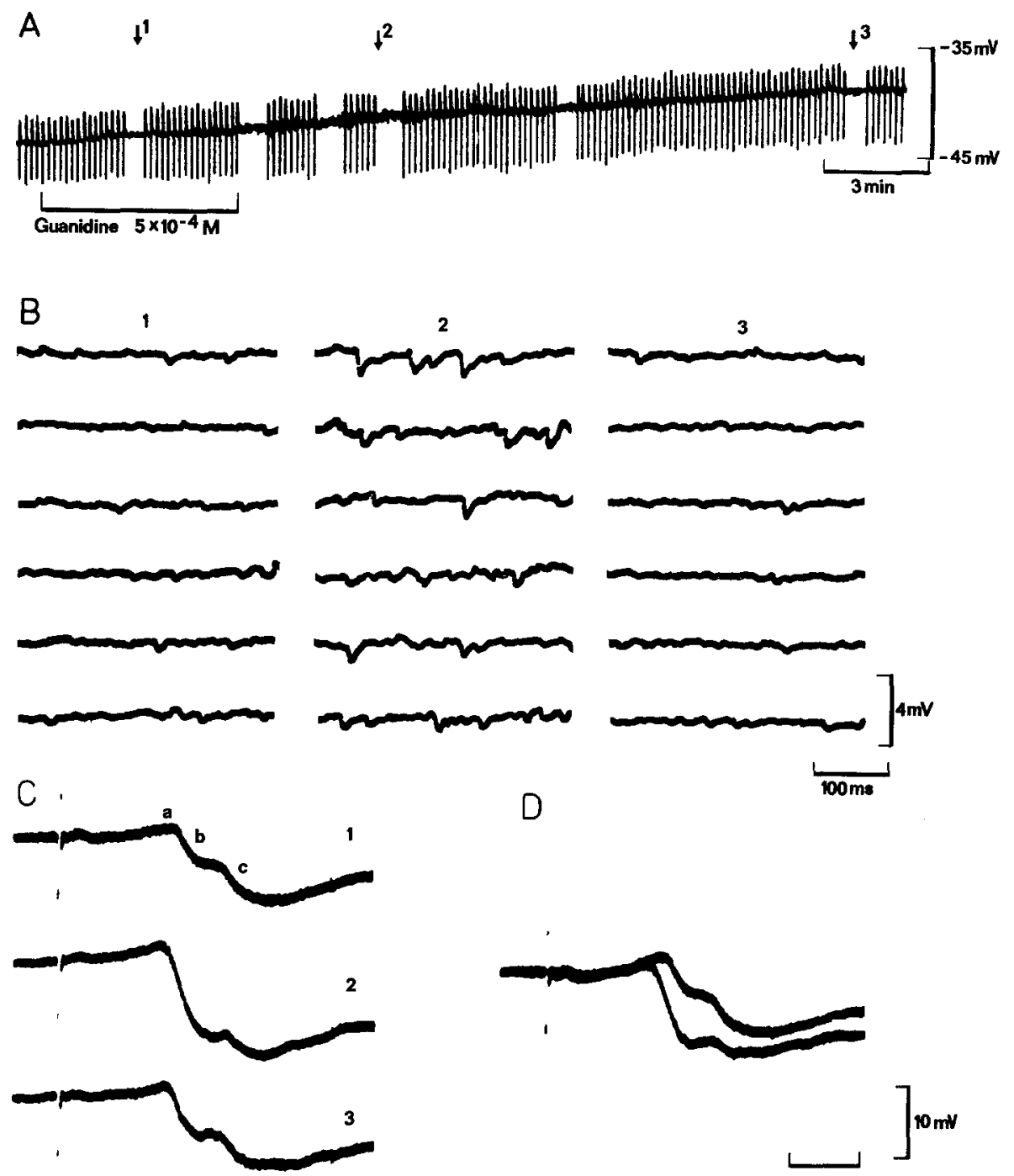

0

The postsynaptic potentials evoked or increased by guanidine were usually depolarizing ones. In spite of this they have to be considered as inhibitory postsynaptic potentials (IPSP) for reasons demonstrated in Figures 2 and 3. In spinal motoneurons of the frog

it is a common feature, that only depolarizing PSPs are recordable (Katz and Miledi, 1963). However, a depolarization of the membrane potential by intracellular current injection reverses one component of the PSP into a hyperpolarizing direction, thus charac- 
terizing it as an IPSP (Fig. 2; Sonnhof et al., 1975). Therefore in Figure 3 the effect of guanidine was analyzed during constant depolarization of a motoneuron by intracellular depolarizing current injections.

Under such conditions it was possible to differentiate between spontaneous depolarizing excitatory postsynaptic potentials (EPSPs) and hyperpolarizing IPSPs (Fig. $3 \mathrm{~B}_{1}$ ). Guanidine $\left(5 \cdot 10^{-4}\right)$ in the bath solution selectively increased the amplitude and frequency of the small hyperpolarizing IPSPs (Fig. $3 \mathrm{~B}_{2}$ )-the depolarizing EPSPs remained unchanged.

In Figure 3C, D the action of guanidine upon postsynaptic potentials following stimulation of the dorsal roots (DR-PSP) is demonstrated. These DR-PSPs consisted of an initial depolarizing component of small amplitude (DR-EPSP; Fig. 3C, a) and a subsequent longer lasting hyperpolarizing potential of 2 different portions (DR-IPSPs; Fig. 3C, b, c). These two hyperpolarizing potentials are well defined as IPSPs, since they have a reversal potential near the resting membrane potential and are accompanied by a strong increase in membrane conductance (not demonstrated). During guanidine application the amplitude and the steepness of the early IPSP (Fig. 3C, D) increased in correspondence with the enhancement of the spontaneously occurring inhibitory potentials. The reversal potential of the IPSPs remained unchanged. The amplitude of the early DR-IPSP reversibly decreased about $30 \mathrm{~min}$ after guanidine application ended (Fig. 3C, 1-3). Additionally a shortening of the latency of the DR-IPSP was observed. The small depolarizing EPSP (Fig. 3C, a), however, remained unchanged.

\section{Effects of Guanidine during High Magnesium Concentration}

Synaptic transmission in the frog spinal cord is blocked by adding magnesium ions to the bath solution (Erulkar et al., 1974; Sonnhof et al., 1977). Under such an experimental condition the action of guanidine was completely abolished. This is illustrated in Figure 4, which shows a continued intracellular recording from the same motoneuron as shown in Figure 1. The spinal cord now was superfused with Ringer solution, in which an equimolar amount of $\mathrm{NaCl}$ was substituted by $15 \mathrm{mM} \mathrm{MgCl} 2$. About $5 \mathrm{~min}$ after the beginning of the superfusion the DR-PSP's were diminished (Fig. 4A) and completely blocked after $9 \mathrm{~min}$. The membrane potential showed a small hyperpolarizing shift at the same time. After that time the effect of guanidine was completely blocked (Fig.4B). Only some very small postsynaptic potentials could be recorded also in the presence of magnesium ions (Fig. 4B). These potentials may originate from a spontaneous transmitter release in synaptic terminals, which cannot be blocked by magnesium (Katz and Miledi, 1963; Erulkar et al., 1974).

\section{Effects of Guanidine in Higher Concentration}

In contrast to the action of guanidine in a concentration of $5 \cdot 10^{-4} \mathrm{M}$ the application of guanidine in a concentration of $5 \cdot 10^{-3} \mathrm{M}$ induced strong and very long lasting effects. As shown in Figure $5 \mathrm{~A}$ guanidine in this concentration very strongly increased the amplitude and the frequency of the spontaneous post-

A

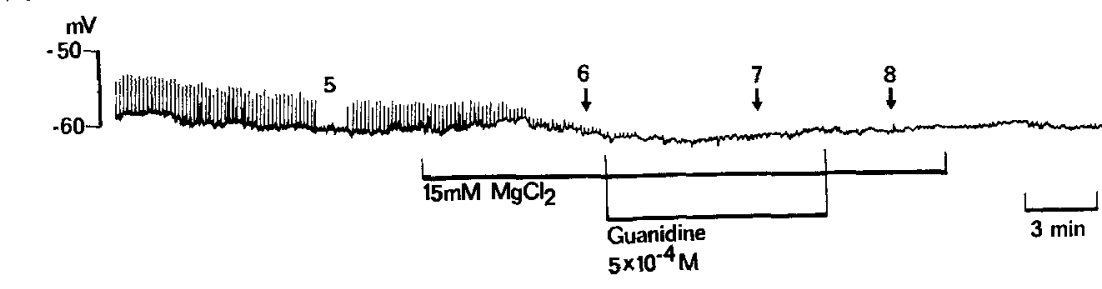

B

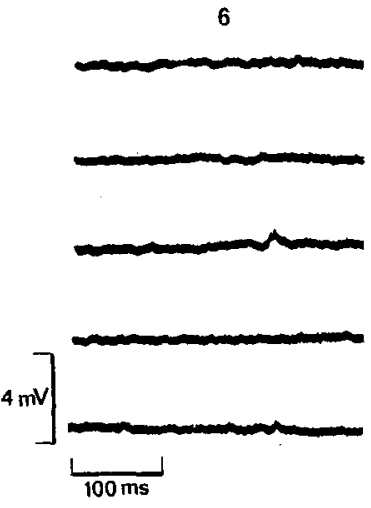

7

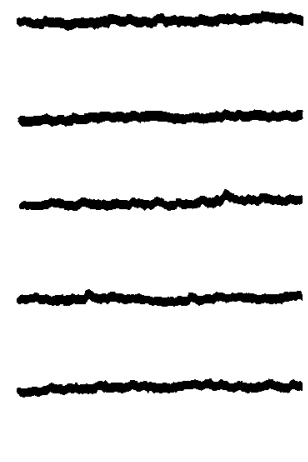

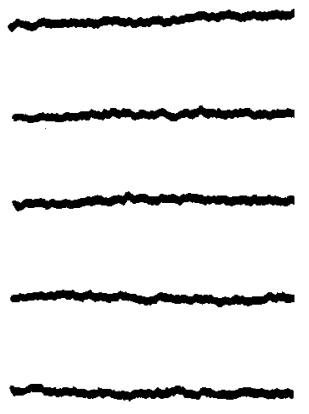

Fig. $4 \mathrm{~A}$ and $\mathrm{B}$

Effect of guanidine during high magnesium concentration. Recording from the same motoneuron as shown in Figure 1. (A and B) Same registration as in Figure 1. During the period indicated by the upper bar normal Ringer solution was replaced by a solution containing $\mathrm{MgCl}_{2}$ in a concentration of $15 \mathrm{mM}$. Note, that guanidine action under such conditions was blocked (application indicated by the lower bar) 
Fig. $5 \mathrm{~A}-\mathrm{C}$

Effect of guanidine in high concentration $\left(5 \cdot 10^{-3} \mathrm{M}\right)$. (A) Intracellular registration of the membrane potential of a spinal motoneuron. Guanidine in a concentration of $5 \cdot 10^{-3} \mathrm{M}$ was applied into the Ringer solution. Note the strong fluctuations of the membrane potential induced by the increase of spontaneous postsynaptic potentials. (B) Registration of the membrane potential from the same motoneuron as in A with higher speed. (C) Registration of the membrane potential oscillations induced by guanidine in high concentration $\left(5 \cdot 10^{-3} \mathrm{M}\right)$ during intracellular current injection. The direction of the oscillations are reversed from a depolarization into a hyperpolarization by shifting the membrane potential from $-60 \mathrm{mV}$ to $-50 \mathrm{mV}$ by $7 \mathrm{nA}$ depolarizing current strength. Vice versa the amplitude of the depolarizing oscillations increased by a hyperpolarization of the membrane potential from $-60 \mathrm{mV}$ to $-70 \mathrm{mV}$ ( $5 \mathrm{nA}$ current strength)
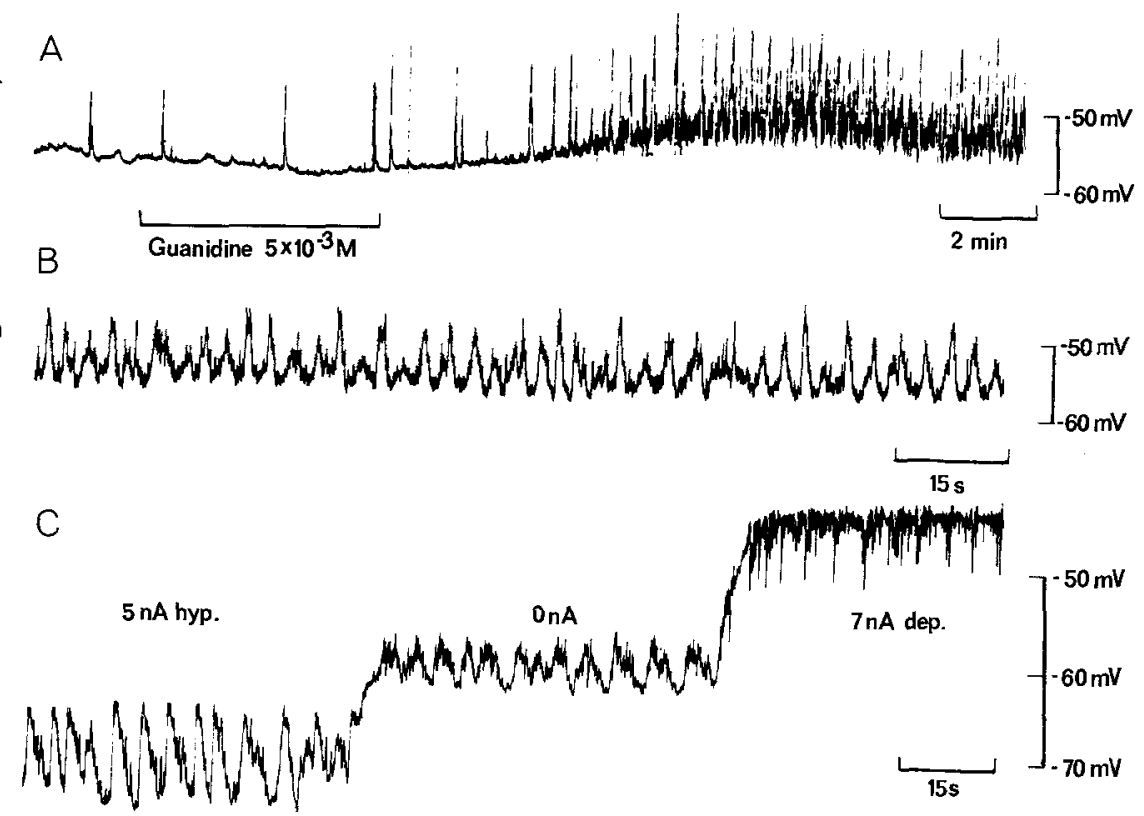

synaptic potentials. After a few minutes these large spontaneous postsynaptic potentials appeared in a rather regular, rhythmic pattern. By summation they produced periodic changes of the resting membrane potential of the motoneurons by about 5 to $10 \mathrm{mV}$ revealing a rather regular frequency of $0.3-0.1 \mathrm{cps}$ (Fig. $5 \mathrm{~B}$ ). These waves of summed synaptic potentials were recorded as long as $3-4 \mathrm{~h}$. In Figure $5 \mathrm{C}$ these slow membrane potential oscillations are investigated by changing the membrane potential of the motoneuron by intracellular current injection. The oscillations are reversed from a depolarizing direction into a hyperpolarizing direction. On the other hand the amplitude of the spontaneous oscillation was increased when the membrane potential was increased by hyperpolarizing current injection. This indicates, that the regular oscillations of the membrane potential induced by guanidine are caused by summation of spontaneous inhibitory postsynaptic potentials with a reversal potential similar to that of the stimulus induced DR-IPSP. All these guanidine effects were completely blocked within 5 min by adding magnesium ions $(15 \mathrm{mM})$ into the bath solution.

\section{DISCUSSION}

Guanidine in our experiments increased the amplitude of inhibitory postsynaptic potentials in spinal motoneurons either occurring spontaneously or induced by stimulation of the dorsal roots. In contrast, EPSP's were uneffected. Extensive measurements on the neuromuscular transmission have shown that guanidine increases the amount of transmitter mole- cules released from nerve endings (Otsuka and Endo, 1960; Kamenskaya et al., 1975a, b; Teräväinen and Larsen, 1975). Our results indicate, that in accordance with the observations of Koizumi (1955), guanidine acts in a similar way also upon the synaptic transmission in the spinal cord.

The increase in the amplitude of inhibitory postsynaptic potentials induced by dorsal root stimulation (DR-IPSP) in the spinal cord of the frog is comparable with the enhancement in the amplitude of endplate potentials caused by guanidine in nervemuscle preparations (Otsuka and Endo, 1960; Kamenskaya et al., 1975 a, b; Teräväinen and Larsen, 1975). The small postsynaptic potentials in spinal motoneurons of the frog originate from action potentials of spontaneously active interneurons and, similar to the miniature endplate potentials of neuromuscular transmission, from a spontaneous transmitter release in the nerve terminals (Katz and Miledi, 1963; Colomo and Erulkar, 1968). Guanidine, however, only enhanced the action potential induced transmitter release, since in contrast to the spontaneous transmitter release, which is resistant to high magnesium concentrations (Katz and Miledi, 1963; Erulkar et al., 1974), stimulus induced synaptic activation, as well as the action of guanidine were blocked by addition of magnesium ions $(15 \mathrm{mM}$ ) into the Ringer solution (see Fig. 4). This observation corresponds to the effect of guanidine on the neuromuscular synapse, where the miniature endplate potentials also remained unchanged (Kamenskaya et al., 1975a, b; Teräväinen and Larsen, 1975). Additionally Otsuka and Endo (1960) observed spontaneously appearing "giant potentials" 
in guanidine treated nerve-muscle preparations. Based on this finding they proposed a transmitter release caused by a spontaneous excitation of presynaptic points by guanidine. The great increase in frequency of the small postsynaptic potentials in our experiments indicates, that such a spontaneous excitation of presynaptic terminals followed by a release of transmitter molecules beside the enhancement of action potential induced transmitter release is an important action of guanidine.

The best explanation for our results seems to be an effect of guanidine on some specific presynaptic terminals. As demonstrated in Figure 3 guanidine enhanced only inhibitory postsynaptic potentials. Also with high concentration the increase of spontaneous inhibitory potentials was the main effect of guanidine (see Fig. 5). But it remains unclear, whether guanidine facilitates the transmitter release by direct action on inhibitory afferent terminals or indirectly by an action on nerve endings impinging on inhibitory interneurons. To answer the question whether guanidine, like in the neuromuscular transmission, selectively acts on acetylcholine containing synaptic terminals more experimental work has to be done. The enhancement of acetylcholine release from axon collaterals of motoneurons is possible, the synaptic pathway, however, of recurrent inhibition in frog spinal cord is not yet clear. A recurrent postsynaptic inhibition from Renshaw type is absent in frog spinal cord (for review see Simpson, 1976).

It is difficult to explain the described therapeutic effect of guanidine in the treatment of amyotrophic lateral sclerosis (Norris et al., 1974). The main problem is the unknown etiology of the amyotrophic lateral sclerosis. But one possible effect of guanidine therapy may be, that a permanent activation of the postsynaptic membrane by small postsynaptic potentials may have a trophic effect upon motoneurons which counteracts the degenerative process of the disease. From clinical view beside such a assumed therapeutic effect the described side effects of guanidine, which may be serious (bone marrow depression), have to be considered (Norris et al., 1974; Wiederholt, 1975).

Acknowledgements. We thank Dr. D.W. Richter and Dr. H. Camerer for helpful discussions als well as Mrs. G. Froelich for the preparation of the figures. It is a pleasure to thank Mr. R. Förderer for his great help in the improvement of the technical equipment.

\section{REFERENCES}

Colomo, F., Erulkar, S. D.: Miniature synaptic potentials at frog spinal neurones in the presence of tetrodotoxin. J. Physiol. (Lond.) 199, 205-221 (1968)

Erulkar, S. D., Dambach, G. E., Mender, D.: The effect of magnesium at motoneurons of the isolated spinal cord of the frog. Brain Res. 66, 413 - 424 (1974)

Gergens, E., Baumann, E.: Über das Verhalten des Guanidin, Dicyandiamidin and Cyanamid im Organismus. Arch. Ges. Physiol. 12, 205-214 (1876)

Kamenskaya, M. A., Elmquist, D., Thesleff, S.: Guanidine and neuromuscular transmission. 1. Effect on transmitter release occurring spontaneously and in response to single nerve stimuli. Arch. Neurol. 32, 505-509 (1975a)

Kamenskaya, M. A., Elmquist, D., Thesleff, S.: Guanidine and neuromuscular transmission. 2. Effect on transmitter release in response to repetitive nerve stimulation. Arch. Neurol. 32, 510 $518(1975$ b)

Katz, B., Miledi, R. : A study of spontaneous miniature potentials in spinal motoneurones. J. Physiol. (Lond.) 168, $389-422$ (1963)

Koizumi, K.: Tetanus and hyperresponsiveness of the mammalian spinal cord produced by strychnine, guanidine, and cold. Am. J. Physiol. 183, 35 - 43 (1955)

Lambert, E. H., Elmquist, D.: Quantal components of endplate potentials in the myasthenic syndrome. Ann. N.Y. Acad. Sci. 183, $183-199$ (1971)

Norris, F. H., Calanchini, P. R., Fallat, R. J., Panchari, S., Jewett, B.: The administration of guanidine in amyotrophic lateral sclerosis. Neurology 24, 721 - 728 (1974)

Oh, S. J., Kim, K. W.: Guanidine hydrochloride in the EatonLambert syndrome. Electrophysiologic improvement. Neurology 23, $1084-1090$ (1973)

Otsuka, M., Endo, M.: The effect of guanidine on neuromuscular transmission. J. Pharmacol. Exp. Ther. 128, 273 -282 (1960)

Ricker, K., Döll, W.: Treatment of botulism with guanidine. Z. Neurol. 198, $332-341$ (1970)

Scaer, R. C., Tooker, J., Cherington, M.: Effect of guanidine on the neuromuscular block of botulism. Neurology 19, $1107-1110$ (1969)

Simpson, J. I.: Functional synaptology of the spinal cord. In: Frog neurobiology (R. Llinás, W. Precht, eds.), pp. $743-746$. Berlin-Heidelberg-New York: Springer 1976

Sonnhof, U., Richter, D. W., Taugner, R.: Electrotonic coupling between frog spinal motoneurons. An electrophysiological and morphological study. Brain Res. (in press, 1977)

Sonnhof, U., Grafe, P., Krumnikl, J., Linder, M., Schindler, L.: Inhibitory postsynaptic actions of taurine, GABA and other amino acids on motoneurons of the isolated frog spinal cord. Brain Res. 100, 327 - 341 (1975)

Teräväinen, H., Larsen, A.: Effect of guanidine on quantal release of acetylcholine in the mammalian myoneural junction. Exp. Neurol. 48, $601-609$ (1975)

Wiederholt, W. C.: Guanidine hydrochloride therapy in neuromuscular disorders. West. J. Med. 123, 132 -133 (1975)

Received July 12/Accepted October 13, 1977 